\title{
THE INFLUENCE OF USER ACTIVITY AND ENVIRONMENTAL CHARACTERISTICS DIMENSIONS ON SENSE OF PLACE IN CITY PARKS
}

\author{
Ivan Danny Dwiputra ${ }^{1 *}$, Angela Christysonia Tampubolon ${ }^{2}$, Hanson E. Kusuma ${ }^{3}$ \\ ${ }^{1}$ Graduate Student, Department of Architecture, Institut Teknologi Bandung, Indonesia \\ ${ }^{2}$ Lecturer, Department of Architecture, Universitas Kristen Petra, Indonesia \\ ${ }^{3}$ Associate Professor, Department of Architecture, Institut Teknologi Bandung, Indonesia \\ "Corresponding author; Email: ivan.danny25@gmail.com
}

\begin{abstract}
City parks have certain environmental characteristics and accommodate various types of activities that affect the sense of place of the user. This study was conducted with the aim of identifying the dimensions of user activities and environmental characteristics, and sense of place levels related to city parks, as well as the causal relationships between them. Qualitative research was done using an online survey with open-ended questions. The collected text data were analyzed using content analysis. Quantitative research was done using an online survey with closed-ended questions that were compiled based on the results of the qualitative research analysis. The collected numerical data were analyzed by factor analysis and multivariate regression analysis. The analysis revealed four user activity dimensions (recreation, social interaction, work, and sports and hobby), seven environmental characteristics dimensions (natural environment, design, facilities, comfort, location, proximity, and entertainment), and two sense of place dimensions (compatibility with a place and dedication to a place). The dimension compatibility with a place tended to be influenced by the accessibility and visual quality of a park (location, natural environment, and park design), while the dimension dedication to a place tended to be influenced by user engagement (sport and hobby, and facilities).
\end{abstract}

Keywords: Cmpatibility with a place; dedication to a place; dimension of activity; dimension of environmental characteristics; sense of place levels.

\section{INTRODUCTION}

Open space is a spatial element that must exist in an urban context. This type of space is located outside building masses and can be used by everyone and also provides opportunities for various activities (Hakim, 2003). Jan Gehl (1996) in his book Life Between Buildings presents tree groups of open-space activities: necessary activities, optional activities, and social activities. A city park is a type of open space that is 'active'. Parks are planned and provided to meet the needs of city dwellers. Active city parks contain elements that facilitate activities, such as playing, sports, or walking around. This type of city park can be a plaza, a sports field, a playground for children and adolescents as well as river greenery as a place for recreation.

Stephen Carr (1992) and Carmona (2003) identify five basic needs that affect a person's preferences for public space. (1) Comfort, which is the main key to the success of a public space where the length of time a person spends in a public space is a function and an indicator of comfort. Comfort is influenced by environmental conditions such as wind and sunlight, and facilities such as comfortable and sufficient seating. (2) Relaxation, which is included in psychological comfort but is more related to body and mind. Natural characteristics such as trees, plants, and water features affect one's psychological comfort. Therefore, the created atmosphere can have a relaxing effect on the body. (3) A person's passive engagement with the environment can create a relaxed feeling. The key element of passive engagement is the activity of watching. For example, observation, scenery, public art, formal performances or informal entertainment, and linkages with nature are elements that affect passive engagement. (4) Active engagement, which is a direct experience between a person and a place, and people present in said place who can provide opportunities for contact and social interaction. Elements of the environment are also involved in the social interaction that occurs. (5) Discovery, which represents the desire for a pleasant experience when one is in a certain location. It also involves more deliberate actions by those who are responsible for managing and vitalizing the public sphere. Discovery may include entertainment events such as performances, art exhibitions, street theater, live music, markets, and social events.

Steele (1981) mentions physical elements that affect the sense of place, such as area, components, diversity, texture, decoration, color, odor, and noise. Steele states furthermore that identity, history, entertainment, fun things, beauty, vitality, and memory 
also have an effect on how individuals interact with a place. According to Steele (1981), sense of place is an interactional concept, where a person comes into contact with a place, which produces reactions. These reactions include feelings, perceptions, behaviors, and impacts associated with the presence of a person in a particular location. Jorgensen and Stedman (2001) claim that sense of place is not only imbued in a physical arrangement but also comes from the human interpretation of the arrangement. Altman and Low (2001) mention the existence of place attachment, which is defined as a positive bond between an individual or a group with an environment.

According to Shamai (1991), sense of place is an abstract, unclear and vague concept; a combination of a physical place and social interaction in that place. Subsequently, Shamai (1991) formulated levels of sense of place, ranging from Not having any sense of place, Knowledge of being located in a place, Belonging to a place, Attachment to a place, Identifying with the place's goals, Involvement in a place, and Sacrifice for a place. In accordance with the research on levels of Relph (1976), Shamai (1991) mentions that if people have a sense of place, it means that they show emotions connected to that place, they have a feeling of belonging to that place, they care about that place, up to being willing to make sacrifices for that place. The place is very meaningful and significant to them.

Until now, research on sense of place has tended to discuss the meanings, categories, and levels of sense of place. Architectural and urban studies that explain the relationship between sense-of-place factors tend to discuss activities, physical settings, and meanings. The authors of the present paper have not found a study that discusses the factors that increase or decrease the level of sense of place of a person in city parks. Therefore, this study focused on identifying the dimensions of user activities and environmental characteristics, and sense of place levels related to city parks. The goal is to find a causal relationship between the user activity and environmental characteristics dimensions and people's sense of place in a city park.

\section{METHODOLOGY}

This research used a qualitative-quantitative approach in a sequential mixed-method design (Creswell, 2008) comprising explorative and explanatory research (Groat \& Wang, 2002). The explorative qualitative research was conducted to obtain data containing information about the motivations (activities) and reasons of respondents to go to a city park (characteristics). The quantitative explanatory research aimed to reveal causal relationships between the dimensions of user activities and environmental characteristics of a place on the one hand, and the sense of place of respondents in a city park on the other hand.

Data collection was done through a survey method in the form of an online questionnaire. The questionnaire was distributed by snowball non-random sampling (Kumar, 2005) through acquaintance contacts. They were asked to spread the online questionnaire to family, friends or colleagues. In the first phase of the research, data were collected from 28 August to 3 September 2017 through an online questionnaire containing open-ended qualitative questions. The respondents were asked to write down their motivation to go to a city park and their preferential environmental characteristics. Each answer was analyzed using content analysis to identify and categorize keywords from the captured text data.

The results of the content analysis of the reasons for going to a city park were used to compile closedended questions about the types of activities undertaken in city parks. Fifteen types of activities were designated, i.e. 'sightseeing', 'playing', 'relax', 'photography', 'family interaction', 'discussion', 'friend interaction', 'meeting', 'academic duty', 'reading books', 'working', 'lobbying', 'hobbies', and 'sports'.

The analysis results of the questionnaire on environmental conditions were used to compile closedended questions about the characteristics of the urban park environment. Twenty-two environmental characteristics variables were designated, i.e. "number of trees', 'natural imagery', 'scenery', 'natural atmosphere', 'design', 'toilet and mosque', 'garden size', 'visitor atmosphere', 'playground', 'sports arena', 'entertainment facility', 'cleanliness', 'comfort', 'seating', 'water element', 'location', 'accessibility', 'proximity', 'noise'.

In the second stage, data were collected by an online closed-ended questionnaire. The question variables were derived from the outcome of the first research stage. The online questionnaires were distributed from October 23 to October 30 2017. The total number of respondents was 152 people, with $46.7 \%$ male respondents and $53.3 \%$ female respondents. They were all domiciled in Bandung city. The respondents were asked about the type of activities performed, their perception of environmental characteristics, and the sense of place felt when in a city park through closed-ended questions compiled using the semantic differential method (SD-method) and Likert scale. Each question had an answer on a scale from 1 to 5 between two opposite poles. Table 1 shows three sample questions from the online questionnaire. 
Table 1. Sample of Closed-ended Questions

\begin{tabular}{ccc}
\hline Variable & \multicolumn{2}{c}{ Example } \\
\hline \multirow{2}{*}{ Activities } & \multicolumn{2}{c}{ Go to the city park to work out } \\
\cline { 2 - 2 } & never & always \\
\hline \multirow{2}{*}{$\begin{array}{c}\text { Characteristics } \\
\text { of the park }\end{array}$} & $\begin{array}{c}\text { The atmosphere of the city park's natural } \\
\text { image }\end{array}$ \\
\cline { 2 - 2 } Sense of place & artificial & natural \\
\cline { 2 - 2 } & \multicolumn{2}{c}{ Feel owns the city park } \\
\hline strongly disagree & $\begin{array}{c}\text { strongly } \\
\text { agree }\end{array}$ \\
\hline
\end{tabular}

Through this questionnaire, numerical data from the respondents were obtained, which were then analyzed quantitatively.

\section{RESULTS AND DISCUSSION}

The data were analyzed by principal component analysis (PCA), factor analysis (FA), followed by multivariate regression analysis. The determination of the principal components (eigenvectors) resulting from the principal component analysis refers to Kaiser's stopping rule (1960). Steven (1986) and Grimm \& Yarnold (1995) state that the application of a stopping rule is more accurate in the application of less than 30 variables. Hence, Kaiser's stopping rule was appropriate for this study. It was applied by extracting the number of major components with eigenvalues greater than one. This means that they had values that exceeded the variability of the measured variables so they could be used to represent the measured variables.

The next step was carrying out factor analysis to find latent variables (dimensions) that can be given a new name. Each major component was rotated using orthogonal varimax rotation to ensure that the components were not correlated. The factor loading of each measured variable associated with a latent variable (dimension) was determined as widely as possible and the factor loading unrelated to the latent variable was determined until it was close to zero.

From the result of the principal component analysis of the activities, four main components with eigenvalue value greater than one were found (with a cumulative percentage of $61,58 \%$ ). These were considered sufficient to describe and represent the phenomenon of the measured variables of user activities. The latent variables generated from the factor analysis are shown in Table 2. The four latent variables describing and representing the dimensions of user activities in city parks were 'recreation', 'social interaction', 'working', and 'sport and hobby'.

From the results of the factor analysis, it can be stated that recreation is a way to revitalize the soul, such as sightseeing, photography, playing and relaxing with family. Social interaction is an activity in which all activities depend on the presence of others in a public space, such as having a discussion, meeting with friends, doing academic tasks, reading books, and eating and drinking. Working activities involve livelihoods such as office tasks or lobbying. Sport and hobby are related to forms of body revitalization such as jogging, walking, or hobbies related to sports. Referring to Jan Gehl's (1996) theory in Life Between Buildings, the latent variables of activities in city parks can be divided into two groups. The first group contains activities of choice (optional activities) namely, recreation, working, and sports and hobby. The second group contains social activities (social activities) that consist of social interaction.

Table 2. Dimensions of Activities

\begin{tabular}{lcccc}
\hline \multicolumn{1}{c}{ Variable } & Recreation & $\begin{array}{c}\text { Social } \\
\text { Interaction }\end{array}$ & Working & $\begin{array}{c}\text { Sport and } \\
\text { Hobby }\end{array}$ \\
\hline Sightseeing & $\mathbf{0 . 8 1}$ & 0.06 & 0.07 & -0.01 \\
Playing & $\mathbf{0 . 7 7}$ & 0.27 & -0.08 & 0.28 \\
Relax & $\mathbf{0 . 6 9}$ & 0.31 & -0.17 & 0.31 \\
Photography & $\mathbf{0 . 6 3}$ & 0.27 & 0.16 & 0.10 \\
Family interaction & $\mathbf{0 . 5 4}$ & -0.43 & 0.27 & 0.09 \\
Discussion & 0.12 & $\mathbf{0 . 7 1}$ & 0.35 & -0.01 \\
Friend interaction & 0.33 & $\mathbf{0 . 7 1}$ & -0.02 & 0.13 \\
Meeting & 0.14 & $\mathbf{0 . 6 4}$ & 0.02 & 0.28 \\
Academic tasks & -0.08 & $\mathbf{0 . 5 8}$ & 0.43 & 0.12 \\
Eating and drinking & 0.33 & $\mathbf{0 . 5 3}$ & 0.07 & -0.05 \\
Reading & 0.03 & $\mathbf{0 . 3 9}$ & 0.36 & 0.33 \\
Job & 0.04 & 0.08 & $\mathbf{0 . 8 6}$ & 0.06 \\
Lobbying & 0.08 & 0.14 & $\mathbf{0 . 8 2}$ & 0.15 \\
Sport & 0.22 & -0.04 & 0.06 & $\mathbf{0 . 8 5}$ \\
Hobby & 0.13 & 0.27 & 0.24 & $\mathbf{0 . 7 4}$ \\
\hline
\end{tabular}

Based on the analysis of the factors related to environmental characteristics, seven main components with eigenvalue greater than one were found (with a cumulative percentage of $66.82 \%$ ), which were considered sufficient to describe and represent the phenomena of 22 measured variables. The latent variables derived from the factor analysis are shown in Table 3. The seven latent variables describing and representing environmental characteristics or community preferences of urban parks are 'natural environment', 'design quality', 'facilities', 'comfort', 'location', 'proximity', and 'entertainment'.

Based on the latent variables obtained, people tend to assess urban park environments especially from the point of view of nature (Prihutami, 2008) and attractive design quality, adequate facilities, cleanliness, and comfort, having a location that is easy to reach and close to centers of activity (Carr, 1992). 
Table 3. Dimension of Physical Characteristics.

\begin{tabular}{lccccccc}
\hline \multicolumn{1}{c}{ Variable } & $\begin{array}{c}\text { Natural } \\
\text { Environment }\end{array}$ & $\begin{array}{c}\text { Design } \\
\text { Quality }\end{array}$ & Facilities & Comfort & Location & Proximity & Entertainment \\
\hline Number of trees & $\mathbf{0 . 8 2}$ & 0.23 & 0.04 & 0.00 & 0.13 & 0.05 & -0.07 \\
Nature imagery & $\mathbf{0 . 7 7}$ & -0.16 & 0.13 & 0.15 & -0.13 & -0.07 & 0.10 \\
Scenery & $\mathbf{0 . 7 3}$ & 0.31 & 0.03 & 0.17 & 0.05 & 0.05 & 0.00 \\
Air comfort & $\mathbf{0 . 6 9}$ & 0.05 & -0.02 & 0.22 & 0.21 & 0.17 & 0.05 \\
Design appeal & 0.17 & $\mathbf{0 . 7 0}$ & 0.06 & 0.28 & -0.02 & 0.03 & 0.16 \\
Toilet \& musalla & -0.11 & $\mathbf{0 . 6 6}$ & 0.22 & 0.26 & -0.03 & 0.03 & -0.29 \\
Park size & 0.49 & $\mathbf{0 . 6 5}$ & 0.17 & -0.08 & 0.14 & -0.04 & 0.04 \\
Visitors atmosphere & 0.13 & $\mathbf{0 . 5 9}$ & 0.16 & 0.01 & 0.37 & 0.06 & 0.24 \\
Playground & -0.09 & 0.10 & $\mathbf{0 . 8 4}$ & 0.10 & -0.04 & 0.04 & -0.23 \\
Sports arena & 0.33 & 0.05 & $\mathbf{0 . 7 8}$ & -0.13 & -0.09 & 0.02 & 0.03 \\
Entertainment facilities & -0.02 & 0.30 & $\mathbf{0 . 7 6}$ & 0.14 & -0.04 & -0.10 & 0.19 \\
Cleanliness & 0.09 & 0.17 & -0.08 & $\mathbf{0 . 8 5}$ & 0.10 & 0.10 & 0.03 \\
Amenities & 0.36 & 0.19 & 0.10 & $\mathbf{0 . 5 7}$ & 0.20 & 0.02 & -0.29 \\
Bench amount & 0.23 & 0.04 & 0.40 & $\mathbf{0 . 5 3}$ & 0.23 & -0.06 & 0.05 \\
Water feature & 0.17 & 0.40 & 0.14 & $\mathbf{0 . 4 7}$ & -0.34 & 0.06 & 0.38 \\
Park location & -0.01 & 0.12 & -0.10 & 0.06 & $\mathbf{0 . 7 9}$ & 0.14 & 0.18 \\
Accessibility & 0.19 & 0.02 & -0.01 & 0.18 & $\mathbf{0 . 7 3}$ & 0.18 & 0.05 \\
Near workplace & 0.07 & 0.09 & -0.05 & 0.06 & 0.11 & $\mathbf{0 . 8 4}$ & -0.14 \\
Near school & 0.08 & -0.06 & 0.16 & -0.08 & -0.02 & $\mathbf{0 . 6 6}$ & 0.44 \\
Near home & 0.01 & 0.00 & -0.09 & 0.09 & 0.35 & $\mathbf{0 . 5 9}$ & 0.01 \\
Noise & 0.41 & 0.04 & 0.12 & 0.01 & -0.20 & 0.24 & $\mathbf{- 0 . 6 2}$ \\
Near entertainment venues & 0.22 & 0.20 & 0.01 & 0.01 & 0.23 & 0.20 & $\mathbf{0 . 6 2}$ \\
\hline
\end{tabular}

From the result of the principal component analysis of sense of place, there were two main components with eigenvalue greater than one (with a cumulative percentage of $65.81 \%$ ), which were considered sufficient to describe and represent the phenomena of six measured variables. The latent variables derived from the factor analysis are shown in Table 4. They describe and represent the respondents' two levels of sense of place in urban parks, namely compatibility with a place and dedication to a place.

Table 4. Dimension of Sense of Place

\begin{tabular}{lcc}
\hline \multicolumn{1}{c}{ Variable } & $\begin{array}{c}\text { Compatibility with a } \\
\text { place }\end{array}$ & Dedication to a place \\
\hline Belongings & $\mathbf{0 . 8 0}$ & -0.22 \\
Place goals & $\mathbf{0 . 7 9}$ & 0.22 \\
Attachment & $\mathbf{0 . 7 2}$ & 0.32 \\
Knowledge & $\mathbf{0 . 6 0}$ & 0.31 \\
Involvement & 0.23 & $\mathbf{0 . 8 1}$ \\
Sacrifice & 0.05 & $\mathbf{0 . 9 0}$ \\
\hline
\end{tabular}

The first dimension of the result of the factor analysis represents the measured variable of sense of belonging, the understanding of place goals, place attachment, and knowledge of being located in a particular place. These four measured variables represent the state of a person perceiving and understanding the characteristics of a place; feeling happy, comfortable, and wanting to stay longer (Rachman and Kusuma, 2015); the suitability of a place to their wants and needs; and feeling as if a place is a part of themselves or a sense of belonging to the place. Therefore, the dimensions representing these four measured variables were called 'compatibility with a place', which means conformity, compatibility, or alignment between the quality of a place and one's preferences. The naming compatibility with a place refers to one of the attention restorative theory (ART) criteria compiled by Kaplan (1995). In ART, Kaplan specifies the compatibility criterion, among others, which means the goodness-of-fit between a place and a person, where the place can have a restorative effect on that person. The second dimension of sense of place represents the measured variable of involvement' and 'sacrifice' to a place. Involvement means one's willingness to spend time, energy, and expenses to participate in or contribute to a place. Sacrifice refers to one's commitment and responsibility to prioritize a place over one's own personal interests. The meaning of involvement and sacrifice can be represented by the word 'dedication'. In the MerriamWebster dictionary, dedication means 'self-sacrificing devotion and loyalty'.

From the result of the factor analysis, compatibility with a place is the first dimension and dedication to a place is the second dimension. The first dimension had a higher level of variability than the 
second dimension, i.e. the first dimension has the ability to explain more data than the second dimension. It can also be said that the first dimension was more dominant than the second dimension. The number of people who felt compatibility with a place tended to outweigh the number of people who felt dedication to a place. The tendencies in our findings correspond to the levels of sense of place mentioned by Shamai (2011) (Table 5).

Compatibility with a place is equivalent to or represents the level of "knowledge of being located in a place', 'belonging to a place', 'attachment to a place', 'identifying with a place's goals'. Dedication to a place is equivalent to or represents the level of 'involvement in a place' and 'sacrifice for a place'. Among the levels defined by Shamai (2011), dedication to a place has a higher level of sense of place than compatibility with a place.

Table 5. Comparison between Shamai's Sense of Place and Factor Analysis Result

\begin{tabular}{cc}
\hline Shamai (2011) & Dwiputra (2017) \\
\hline Not having any sense of place & - \\
\hline Knowledge of being located in a & \\
place & Compatibility with a \\
Belonging to a place & \\
Attachment to a place & \\
Identifying with a place's goals & \\
\hline Involvement in a place & Dedication to a place \\
Sacrifice for a place & \\
\hline
\end{tabular}

Table 6. Result of Multivariate Regression Analysis

\begin{tabular}{|c|c|c|c|c|}
\hline \multirow[b]{2}{*}{ Independent } & \multicolumn{2}{|c|}{$\begin{array}{c}\text { Compatibility with } \\
\text { a place } \\
R S q=0.40 P<.0001\end{array}$} & \multicolumn{2}{|c|}{$\begin{array}{l}\text { Dedication to a place } \\
R S q=0.17 P=0.0305\end{array}$} \\
\hline & B & $\mathrm{p}$ & $\beta$ & $p$ \\
\hline Recreation & 0.06 & $\begin{array}{l}0 . \\
47\end{array}$ & -0.13 & 0.15 \\
\hline Interaction & 0.15 & 0.06 & 0.11 & 0.26 \\
\hline Working & -0.01 & 0.86 & 0.06 & 0.51 \\
\hline Sports and hobby & -0.09 & 0.28 & $0.22^{*}$ & 0.03 \\
\hline Natural environment & $0.34^{* * *}$ & $<0.0001$ & 0.07 & 0.44 \\
\hline Design quality & $0.22^{* *}$ & 0.005 & 0.06 & 0.49 \\
\hline Facilities & 0.04 & 0.62 & $0.22^{* * *}$ & 0.01 \\
\hline Comfort & 0.07 & 0.41 & 0.05 & 0.59 \\
\hline Location & $0.38^{* * *}$ & $<0.0001$ & -0.04 & 0.64 \\
\hline Proximity & 0.07 & 0.36 & -0.06 & 0.54 \\
\hline Entertainment & 0.11 & 0.16 & -0.05 & 0.54 \\
\hline
\end{tabular}

All of the dimensions of activities, environmental characteristics, and sense of place were analyzed using multivariate regression analysis to determine the causal relationships between the three groups of dimensions. According to the principle of causal relationships, independent variables should be predecessors of dependent variables. Sense of place can only be felt after a person knows and understands the characteristics of a place and has performed activities in that place. Therefore, in this study, the dimensions of user activities and environmental characteristics were treated as independent variables, whereas the dimensions of sense of place were treated as dependent variables. Table 6 shows the results of the multivariate regression analysis.

The results of the regression analysis in Table 6 show significant causal relationships between location ( $\beta=0.38, p<0.0001)$, natural environment $(\beta=0.34$, $\mathrm{p}<0.0001)$, and design quality $(\beta=0.22 ; \mathrm{p}=0.005)$ as the dominant factors causing a person's compatibility with a city park (compatibility with a place). There is also a significant causal relationship between sport and hobby activities $(\beta=0.22, \mathrm{p}=$ $0.03)$ and adequate facilities $(\beta=0.22 ; \mathrm{p}=0.01)$ as dominant factors causing a person's dedication to a city park (dedication to a place).

Of all the dimensions of activities and environmental characteristics, location, natural environment, and design quality have the most influence on compatibility with a city park. The dimension of location represents a central location and accessibility. Accessibility is the most important factor in determining the success of a public space (Whyte, 2000) and in influencing the degree of user satisfaction with a public space (Erkip, 1997). Ease of accessibility increases the chance of a visit to a city park and increases familiarity with a city park. Cross (2001) calls the sense of place that grows because of habit/familiarity a biographical relationship. For those who live in cities where traffic tends to get stuck and have a busy day-to-day life, accessibility is an important factor that shapes the relationship between them and a place.

The next dimension that affects compatibility with a city park is the natural environment. This dimension represents the following measured variables: 'number of trees', 'natural imagery', 'landscape', and 'air quality'. Van den Berg, Koole and Van der Wulp (2003), Korpela (2003), Hartig, Book, Garvill, Olsson and Garling (1996) mention that a natural environment tends to be perceived as more beautiful than an artificial environment or urban environment, and can decrease a negative mood and have a restorative effect. Galindo (2000) also mentions the enjoyment of nature, which enhances fun and gives a positive influence on a person's psychological wellbeing.

The next dimension that also had a significant influence was the dimension of design quality, which represents the variable of design attractiveness, the presence of toilets and a musalla, the size of the garden, and the atmosphere created by the visitors. 
These four measured variables tend to represent the visual qualities of a city park. Beautiful visual qualities attract attention, invite people to visit, and enhance the impression of a place. This is similar to Carr's (1992) statement relating the need for visual quality, which increases one's satisfaction with a place. Good visual environmental quality and facilities can improve psychological comfort. Therefore, if a person feels comfortable in a place, the place is successful and makes people stay longer.

Furthermore, among the dimensions of user activities and environmental characteristics, sport and hobby, and facilities most influenced dedication to a city park. The sport and hobby dimension represents the measured variables of sport and hobby. The dimension of facilities represents playgrounds, sports arenas, and entertainment facilities. Sports arena facilities accommodate a park's sports activities. The facilities of playgrounds and entertainment arenas accommodate hobby activities of park users. The dimensions of sport and hobby, and facilities together increase user engagement with a park as well as fulfilling the users' desires and needs for activities they like. Regarding facilities, although not using the same words, Kwanda, Kartono, \& Wonoseputro (2014) also mentioned that amenities (facilities) affect the visitor's positive perceptions of the city park. Fulfilled desires and needs increase user satisfaction, foster loyalty, commitment and responsibility of users of a place.

This understanding is similar to that of Mesch \& Monar (1992), who stated that place attachment is a dimension of place sensitivity and positive emotional attachment, which develop between a place and an individual. In this process, a person's positive experience can develop his or her relationship with a place. There is a direct relationship between the place attachment level and an individual's interest in a place, such as involvement with the facilities in a city park. This phenomenon causes the individual to become more attached to a place, which results in them being more and more concerned about this place (Mesch \& Monar, 1992; Hashemnezhad, 2013).

From the results of the regression analysis (Table 6), the factors were obtained that increase or decrease one's sense of place in a city park. The relationship formed shows a process of sense of place development, which goes from the absence of a sense of place to starting to have compatibility with a place to the emergence of a sense of dedication to a place (Figure 1).

The first level is the dimension compatibility with a place. This feeling tends to appear first to someone and is caused by the accessibility and visual quality of the city park. Visual quality represents the natural environment and design quality. The eyes are the human sense that is capable of accepting most information. Therefore, if a park is easily accessible it will also be easy to see. For example, when someone passes a city park every time he or she is going home, a positive experience that is formed in this person raises a sense of compatibility with that place. This phenomenon seems to fulfill passive engagement as mentioned by Stephen Carr (1992).

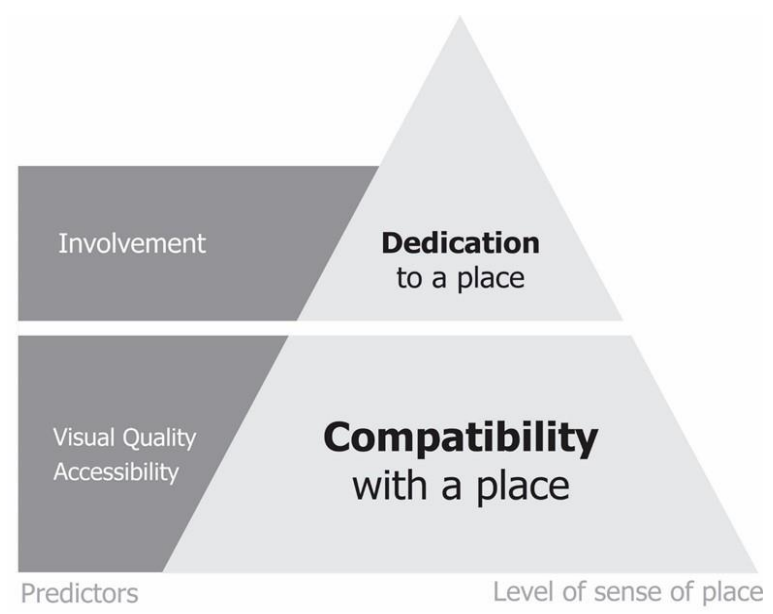

Fig. 1. Model of relationships between levels of sense of place and predictor variables in city parks.

Shamai (2011) revealed that everyone has a different level of sense of place at a certain time and place. Sports arenas and playgrounds that exist in a park trigger actions. A person who has an activity requirement in accordance with available facilities will develop a more positive experience. In the development process, the involvement of the user with the facilities forms an interaction phenomenon. Users become more active because there is conformity between the available facilities and the activities that are desired. This intensive interaction increases one's sense of place or need for a place. Afterwards, when a person has a high need for motivation, there is a readiness to release personal and/or collective interests for the sake of giving more attention to the place at this level. This phenomenon can be interpreted as active engagement (Carr, 1992), which generates a sense of dedication to a place.

\section{CONCLUSION}

This study found four dimensions of user activities and seven dimensions of environmental characteristics related to city parks. The user activity dimensions are: recreation, social interaction, working, and sport and hobby. The environmental characteristics dimensions are: natural environment, design quality, facilities, comfort, location, proximity, and entertain- 
ment. This study also revealed two dimensions of sense of place related to city parks, namely compatibility with a place and dedication to a place. Compatibility with a place is at a lower level and tends to be influenced by accessibility and visual quality (natural environment and design quality). Dedication to a place is at a higher level and tends to be influenced by the active engagement of the user/individual with a place.

This research was conducted in two stages. First, a qualitative explorative research was conducted to identify user activities and environmental characteristics related to city parks. Second, an explanatory quantitative research was conducted to identify the dimensions of activities and environmental characteristics, and reveal their relationships with sense of place. The findings of this study were influenced by the study location and subject. Therefore, research replication is necessary to know the consistency of the findings.

\section{REFERENCES}

Carr, S., Francis, M., Rivlin, L.G., \& Stone, A.M. (1992). Public Space. Cambridge: Cambridge University Press.

Carmona, M. et al. (2003). Public Places-Urban Spaces, the Dimensions of Urban Design. Burlington: Architectural Press.

Creswell, J.W. (2008). Research Design: Qualitative, Quantitative, and Mixed Methods Approaches. California: Sage Publications, Inc.

Cross, J. (2001). What is Sense of Place? 12th Headwaters Conference.

Dewi Surya, S.O. (2016). Korelasi antara Aktivitas di Taman dengan Fungsi Taman serta Elemen Pendukungnya. Prosiding Temu Ilmiah IPLBI 2016. A041-A048.

Erkip, F (1997). The distribution of urban public services: the case of parks and recreational services in Ankara. Cities, 14(6), 353-361.

Galindo, M.P.G. \& Rodríguez, J.A.C. (2000). Environmental Aesthetics and Psychological Wellbeing: Relationships between Preference Judgements for Urban Landscapes and Other Relevant Affective Responses. Psychology in Spain, 4(1), 13-27.
Grim, L.G., \& Yarnold, P.R. (2001). Reading and Understanding Multivariate Statistics. Washington: American Psychological Association.

Gehl, J. (1987). Life between Buildings: Using Public Space. London: Island Press.

Groat, L., \& Wang, D. (2002). Architectural Research Methods. New York: John Wiley \& Sons. Inc.

Hakim, R., \& Utomo, H. (2003). Komponen Perancangan Arsitektur Lansekap. Jakarta: Bumi Aksara

Hartig, T., Book, A., Garvill, J., Olsson, T., \& Garling, T. (1996). Environmental Influences on Psychological Restoration. Scandinavian Journal of Psychology, 37, 378-393.

Hashemnezhad, H., Yazdanfar, A., Heidari, A., \& Behdadfar, N. (2013). Comparison the concepts of sense of place and attachment to place in Architectural Studies. Malaysia Journal of Society and Space. 107-117.

Jorgensen, B. Stedman, R. (2001). Sense of Place as an Attitude: Lakeshore Owners Attitudes toward Their Properties. Journal of Environmental Psychology. 233-248.

Kwanda, T., Kartono, L., \& Wonoseputro, C. (2014). The People's Perceptions on Aesthetic and Uses of the Active Urban Parks in Surabaya. Dimensi - Journal of Architecture and Built Environment, 4l(1), 1-10.

Korpela, K. M. (2003). Negative Mood and Adult Place Preference. Journal of Environment and Behavior, 35, 331-346.

Low, S., \& Altman, I. (1992). Place Atrachment. Newyork: Plenum Press. 1-12.

Prihutami, D. (2008). Ruang Publik Kota yang Berhasil. Skripsi Sarjana Arsitektur Universitas Indonesia.

Shamai, S. (1991). Sense of Place: An Empirical Measurement. Geoforum, 22, 347-358.

Steele, F. (1981). The Sense of Place. Boston: CBI Publishing Company, Inc.

Van den Berg, A.E., Koole, S.L, \& Van der Wulp. N.Y. (2003). Environmental Preference and Restoration: (How) are they related? Journal of Environmental Psychology, 23, 135-146.

Wells, N.M. (2000). At Home with Nature: Effects of 'Greenness' on Children's Cognitive Functioning. Environment and Behavior, 32, 775-795.

Whyte, H.W. (2000). How to Turn a Place Around. Projects for Public Space Inc., US. 